\section{Connecting Structure-Property and Structure-Function Relationships across the Disciplines of Chemistry and Biology: Exploring Student Perceptions}

\section{Kathryn P. Kohn, ${ }^{\dagger *}$ Sonia M. Underwood, ${ }^{*}$ and Melanie M. Cooper ${ }^{\dagger}$}

${ }^{\dagger}$ Department of Chemistry, Michigan State University, East Lansing, MI 48824-1322; "Department

of Chemistry and Biochemistry and STEM Transformation Institute, Florida International University, Miami, FL 33199-2516

\begin{abstract}
While many university students take science courses in multiple disciplines, little is known about how they perceive common concepts from different disciplinary perspectives. Structure-property and structure-function relationships have long been considered important explanatory concepts in the disciplines of chemistry and biology, respectively. Fourteen university students concurrently enrolled in introductory chemistry and biology courses were interviewed to explore their perceptions regarding 1) the meaning of structure, properties, and function; 2) the presentation of these concepts in their courses; and 3) how these concepts might be related. Findings suggest that the concepts of structure and properties were interpreted similarly between chemistry and biology, but students more closely associated the discussion of structure-property relationships with their chemistry courses and structure-function with biology. Despite receiving little in the way of instructional support, nine students proposed a coherent conceptual relationship, indicating that structure determines properties, which determine function. Furthermore, students described ways in which they connected and benefited from their understanding. Though many students are prepared to make these connections, we would encourage instructors to engage in cross-disciplinary conversations to understand the shared goals and disciplinary distinctions regarding these important concepts in an effort to better support students unable to construct these connections for themselves.
\end{abstract}

\section{INTRODUCTION}

The relationship between structure and function is widely recognized as a central and crosscutting concept in science and engineering (National Research Council [NRC], 1996, 2012; College Board, 2009; National Academy of Engineering and National Research Council, 2009; American Association for the Advancement of Science [AAAS], 2011; Tansey et al., 2013; Table 1; Appendix A in the Supplemental Material). Indeed, many authors, curricular documents, and standards explicitly include "structure and function" as a central concept. For example, in biology, Vision and Change (AAAS, 2011) describes six core competencies and five core biological concepts (of which structure and function is one) that can "serve as the basis for any undergraduate biology course." The concept that "basic units of structure define the function of all living things" is applicable across organizational scales and contributes to a foundational understanding of biology for majors and nonmajors alike (AAAS, 2011). However, this fundamental concept extends beyond life sciences education. A Framework for K-12 Science Education: Practices, Crosscutting Concepts, and Core Ideas (referred to as Framework in this paper) identifies structure and function as a crosscutting concept and notes that "the functioning of natural and built systems alike depends on the shapes and relationships of certain key parts as well as on the properties of the materials from
Jennifer Loertscher, Monitoring Editor Submitted January 4, 2018; Revised February 14 2018; Accepted February 15, 2018

CBE Life Sci Educ June 1, 2018 17:ar33 DOI:10.1187/cbe.18-01-0004

*Address correspondence to: Kathryn P. Kohn (pariskat@msu.edu).

(c) 2018 K. P. Kohn et al. CBE-Life Sciences Education @ 2018 The American Society for Cell Biology. This article is distributed by The American Society for Cell Biology under license from the author(s). It is available to the public under an Attribution-Noncommercial-Share Alike 3.0 Unported Creative Commons License (http://creativecommons.org/licenses/ by-nc-sa/3.0)

"ASCB ${ }^{\circledR}$ " and "The American Society for Cell Biology ${ }^{\circledR "}$ are registered trademarks of The American Society for Cell Biology. 
TABLE 1. Structure and function as described in curriculum reform documents

Vision and Change in Undergraduate Biology Education (AAAS, 2011)

\section{A Framework for K-12 Science Education} (NRC, 2012)
"Anchoring Concepts Content Map for General Chemistry" (Holme and Murphy, 2012)

\section{Core Concept: Structure and Function (p. 12)}

Basic units of structure define the function of all living things.

Structural complexity, together with the information it provides, is built upon combinations of subunits that drive increasingly diverse and dynamic physiological responses in living organisms.

Crosscutting Concept: Structure and Function (p. 84)

The way in which an object or living thing is shaped and its substructure determine many of its properties and functions.

Anchoring Concept: Structure and Function (p. 6)

Chemical compounds have geometric structures that influence their chemical and physical behaviors. which they are made" (NRC, 2012, p. 96). This deceptively simple idea is foundational to understanding natural systems ranging from those at the atomic-molecular scale to ecosystems and is inherent to the engineering of products, buildings, and even organizations. Furthermore, as the Framework states, students well versed in this idea should be able to apply their understanding "when investigating phenomena that are unfamiliar to them" and "as critical elements of successful designs" (NRC, 2012, p. 98).

In chemistry, however, discussions of structure and function are not as clearly defined. Although the American Chemical Society Examinations Institute does name structure and function as one of 10 general chemistry anchoring concepts, it appears to be using the terms "function," "behavior," and "properties" synonymously (Table 2; Holme and Murphy, 2012). While these terms are clearly related, most education reform documents make distinctions between them. For example, in the Framework's definition of structure and function, both concepts are discussed: "the way in which an object or living thing is shaped and its substructure determine many of its properties and functions" (NRC, 2012, p. 84). Furthermore, "structure and properties of matter" and "structure and function" are listed as components of disciplinary core ideas in the physical and life sciences, respectively. Similarly, the curricular frameworks for AP Chemistry (College Board, 2014) and AP Biology (College Board, 2015) discuss structure, properties, and function alongside one another without implying that they are the same (Table 2). The relationship between structure and properties has long been considered fundamental to the discipline of chemistry (College Board, 2014; DeFever et al., 2015; Underwood et al., 2016; Cooper et al., 2017) and there has been considerable focus among chemistry education researchers on students' understanding of this relationship (Shane and Bodner, 2006; Cooper et al., 2012a, 2013; Meijer et al., 2013; DeFever et al., 2015; Underwood et al., 2015, 2016). While discussions of structure and function do exist in the chemistry research literature (e.g., Shirota and Kageyama, 2007; Nowinski et al., 2012; Huang et al., 2014; Aussignargues et al., 2016; Schwartz et al., 2016; Melo et al., 2017; Wang et al., 2017), the functions to which they are referring are biological in nature or the researchers are studying the properties of molecular materials to facilitate a desired macroscopic function. As such, we would argue that, while an understanding of function can help contextualize examples in chemistry classrooms, it is the relationship between structure and properties that is foundational to chemistry (Talanquer, 2017). Additionally, function can be applied in both natural and built systems (as noted in the Framework [NRC, 2012]), but such uses have distinct implications about the system origins, as we will discuss further.

For the purpose of this paper, we will move forward with the understanding that structure, properties, and function are closely interconnected concepts but that they can be defined independent of one another (despite the fact that some sources appear to be rather unclear about the differences between them). To understand structure, one must consider the components of the substance and their arrangement and orientation in space. A substance or category of substances (e.g., solids, metals) has a given set of descriptive characteristics, which are termed properties. Finally, Merriam-Webster defines function as "the action for which a person or thing is specially fitted or used or for which a thing exists: purpose" ("Function," n.d.). While unproblematic when considering built systems designed to function in a particular way, such a definition is not directly applicable to natural systems such as those discussed in biology.

Early conceptions of biological function were colored by the teleological ${ }^{1}$ arguments of the time (based on the belief in a divine creator), the implications of which philosophers of biology have since attempted to overcome (Coleman, 1971; Rosenberg and McShea, 2008). Among philosophers, biological function can be interpreted from two, potentially complementary, perspectives-selected effect and causal role (Rosenberg and McShea, 2008). The selected effect interpretation of function suggests that function and adaptation are synonymous, and so it is an understanding of the evolutionary origins that determines a structure's function (Millikan, 1989; Neander, 1991; Amundson and Lauder, 1994; Rosenberg and McShea, 2008). Alternatively, the causal role interpretation of function is based on the idea that the object under consideration is a part of larger system to which it makes a causal contribution (Amundson and Lauder, 1994; Rosenberg and McShea, 2008). In this way, the causal role perspective allows function to be applied in both biological and nonbiological systems. This is reflected in a second definition of function as "any of a group of related actions contributing to a larger action; especially: the normal and specific contribution of a bodily part to the economy of a living organism" ("Function," n.d.).

Despite widespread use of the concept and considerable emphasis on the connection between structure and function, many textbooks fail to define what is meant by the term

\footnotetext{
${ }^{1}$ Teleology, according to the Encyclopedia Britannica, is "explanation by reference to some purpose, end, goal, or function" ("Teleology| philosophy," 2016)
} 
TABLE 2. Structure-properties and structure-function in curriculum reform documents

A Framework for K-12 Science
Education (NRC, 2012)
"Anchoring Concepts Content Map
for General Chemistry" (Holme
and Murphy, 2012)

AP Chemistry Curriculum Framework (College Board, 2014)

AP Biology Curriculum Framework (College Board, 2015)
Crosscutting Concept: Structure and Function (p. 84)

The way in which an object or living thing is shaped and its substructure determine many of its properties and functions.

Core Ideas PS1: Matter and its interactions

(A) Structure and Properties of Matter (p. 106)

Core Ideas LS1: From molecules to organisms: Structure and processes

(B) Structure and Function (p. 143)

Anchoring Concept: Structure and Function (p. 6)

Chemical compounds have geometric structures that influence their chemical and physical behaviors.

(A) Atoms combine to form new compounds that have new properties based on structural and electronic features.

(E) Three-dimensional structures may give rise to chirality, which can play an important role in observed chemical and physical properties.

(F) Reactions of molecules can often be understood in terms of subsets of atoms, called functional groups.

(G) Periodic trends among elements can be used to organize the understanding of structure and function for related chemical compounds.

(H) Many solid-state, extended systems exist, and geometric structures play an important role in understanding the properties of these systems.

Big Idea 2: Chemical and physical properties of materials can be explained by the structure and the arrangement of atoms, ions, or molecules, and the forces between them (p. 19).

Essential Knowledge 2.B.3.e (p.27): The structure and function of many biological systems depend on the strength and nature of the various Coulombic forces.

Big Idea 5

Essential Knowledge 5.D.3.b (p. 62): The functionality and properties of molecules depend strongly on the shape of the molecule, which is largely dictated by noncovalent interactions.

Big Idea 4 (p. 78): Biological systems interact, and these systems and their interactions possess complex properties.

Enduring Understanding 4.A: Interactions within biological systems lead to complex properties. Essential Knowledge 4.A.1: The subcomponents of biological molecules and their sequence determine the properties of that molecule.

Essential Knowledge 4.A.2: The structure and function of subcellular components, and their interactions, provide essential cellular processes.

Essential Knowledge 4.A.4: Organisms exhibit complex properties due to interactions between their constituent parts.

Enduring Understanding 4.B: Competition and cooperation are important aspects of biological systems. Essential Knowledge 4.B.1: Interaction between molecules affect their structure and function "function" itself. For example, Understanding Biology (Mason et al., 2015), the textbook used by the introductory biology course in this study, introduces the relationship between structure and function in the very first chapter as one of seven unifying biological themes. While the authors elaborate on the benefits of understanding such a relationship (e.g., being able to infer the function of a similar structure in different organisms), they do not provide a general definition for either structure or function.

It is more common to find explicit definitions of function in the education research literature, in which it is typically described as either the purpose (Collins and Ferguson, 1993; Ferrari and Chi, 1998; Hmelo et al., 2000; Hmelo-Silver and Pfeffer, 2004; Dauer and Long, 2015; Dauer and Dauer, 2016), role (Hmelo-Silver and Pfeffer, 2004; Hmelo-Silver et al., 2007, 2008; Dauer et al., 2013; Sinha et al., 2013; Jordan et al., 2014; Golick et al., 2017), or outcome/output (Hmelo-Silver et al., 2007, 2008; Dauer et al., 2013; Dauer and Long, 2015; Sinha et al., 2013; Jordan et al., 2014; Yen et al., 2014; Reinagel and Bray Speth, 2016; Golick et al., 2017) of a system or system component. Each of these definitions has implications for how function might be interpreted by students. Purpose suggests intent, role requires the context of a larger system, and outcome indicates that the function is the consequence of some process. One might wonder whether these definitions are equally productive for students or whether the meanings are even compatible, perhaps a question for a future study.

In the biology education literature, there is little research exploring students' conceptual understanding of the relationship between structure and function. However, one use of function has been in the context of structure-behavior-function (SBF) theory. Originating in the disciplines of computer science and engineering (Goel et al., 1996), SBF theory was adapted for biology education research by Hmelo-Silver and coworkers (2000, 2004, 2007), as it considers the causal relationships between structure and function through the identification of mechanisms (i.e., behaviors). More recently, the use of SBF theory has extended into postsecondary education research. The goal of this work was to improve students' ability to connect molecular-level processes to organism- and population-level 
events (Dauer et al., 2013; Dauer and Long, 2015; Bray Speth et al., 2014; Reinagel and Bray Speth, 2016). It is important to note that SBF theory has been used as a research lens and, especially given its origins in the disciplines of computer science and engineering, is not necessarily representative of how the terms "structure," "behavior," and "function" are interpreted by the biology community.

Consideration of function in chemistry is complicated, because some practitioners appear to use the term synonymously with properties. Additionally, given that chemistry principles are applied to understand both natural and built systems (e.g., by those studying molecular biology, geology, or materials science), the use of the term "function" in chemistry may have different implications depending on the context. Furthermore, in chemistry, students may associate the term function with "functional group," which would be closely related to the ways in which groups of atoms behave (i.e., properties such as reactivity). Clearly, the meaning of function is more varied among the science disciplines than that of structure or properties. As such, we felt it necessary to ask students to begin by discussing what such terms meant to them.

\section{PURPOSE OF THE STUDY}

Structure-property and structure-function relationships are central to how experts think about chemistry and biology. They can be used as frameworks for connecting conceptual understanding, constructing explanations, or predicting the effect of a change on a system. The purpose of this study was to explore student conceptions of structure, properties, and function (and the relationship between them) after having encountered elements of these frameworks in their introductory chemistry and biology courses. Typically, more than half of the students who take two semesters of general chemistry are life sciences or pre-professional majors; and chemistry is often listed as a prerequisite (or at least a co-requisite) for introductory biology, presumably so students can use their knowledge of chemical reactions and molecular interactions to think about biological systems. When this study began, the introductory science courses were at various stages of a collaborative transformation process (Cooper et al., 2015). Therefore, the data we present should be considered in the context of courses that were attempting to develop a coherent approach across the disciplines. Our study focused on three research questions:

RQ1: How do students coenrolled in introductory chemistry and biology courses describe the meanings of the terms "structure," "properties," and "function"?

RQ2: How do students coenrolled in introductory chemistry and biology compare their experiences with regard to the presentation of structure, properties, and function (and the relationship between them) in these courses?

RQ3: How do students coenrolled in introductory chemistry and biology courses describe the relationship between structure, properties, and function?

These research questions are deeply interconnected, as students' interpretation of the meaning of the component terms would likely affect their understanding of the relationships presented in their courses and vice versa. Together, this understanding of the terms in context and the presentation of the relationships between them would likely affect how and whether they develop a coherent understanding that spans the disciplines.

\section{METHODS \\ Setting and Participants}

This study was set at a large, public, research university in the Midwest. The student body was predominantly made up of domestic students who self-identified as Caucasian. The student body was composed of approximately 51.7\% women, $18.7 \%$ students of color, and $14.4 \%$ international students. The middle $50 \%$ of students entering the university had an ACT composite score of 24-29.

General Chemistry. At this university, general chemistry for science, technology, engineering, and mathematics (STEM) students is taught as a two-semester sequence (General Chemistry 1 [GC1] and General Chemistry 2 [GC2]). Lecture sections are 350-450 students in size and include a required 1-hour recitation section in addition to the 3 hours a week in lecture. About $35 \%$ of students who take GC1 are also required to take GC2, and the majority of these students pursue life sciences majors. For the purposes of this study, we did not distinguish between the two semesters and instead treated the course as a single entity (GC1/ GC2). At the time, the university was in the process of transitioning from a traditional to a transformed general chemistry curriculum-Chemistry, Life, the Universe and Everything (CLUE)designed to facilitate development of student understanding of four core ideas (one of which is the relationship between structure and properties; Table 3) in a scaffolded intertwined progression (Cooper et al., 2012b; Cooper and Klymkowsky, 2013). Furthermore, the curriculum was designed to consider the needs of the students enrolled, including life sciences and preprofessional majors, and uses biological phenomena to illustrate the underlying chemistry content. Students complete their homework using beSocratic, a freeform, online assessment platform that allows students to construct representations and explanations, as well as revise their work (Bryfczynski, 2012; Bryfczynski et al., 2012; Cooper et al., 2014).

\section{TABLE 3. Course big ideas related to structure, properties, and function}

\begin{tabular}{ll}
\hline CLUE Chemistry (GC1/GC2) $^{\mathrm{a}}$ & $\begin{array}{l}\text { Atomic/molecular structure and properties } \\
\text { The macroscopic physical and chemical properties of a substance are determined by the three-dimensional } \\
\text { structure, the distribution of electron density, and the nature and extent of the noncovalent interactions } \\
\text { between particles. }\end{array}$ \\
Cell and Molecular Biology (B1) & $\begin{array}{l}\text { Structure determines function } \\
\text { At the molecular level, biology is based on dynamic, three-dimensional chemical and physical interactions. } \\
\text { Differences in molecular structures and properties determine molecular and cellular functions. }\end{array}$ \\
\end{tabular}

${ }^{\mathrm{a}}$ As presented in Cooper et al., 2017. 
Introductory Biology. The first introductory biology course (B1), taken primarily by STEM majors, focuses on cell and molecular biology. B1 presents seven core ideas, one of which is "structure determines function," described in the syllabus as the idea that differences in molecular structures and properties determine molecular and cellular functions (Table 3). The seven core ideas were determined by the faculty instructors through extensive discourse based on the concepts presented in a variety of curricular reform documents (e.g., Association of American Medical Colleges, 2009; AAAS, 2011; NRC, 2012). At the beginning of each unit, the applicable core ideas are discussed in the context of that unit's material. Lecture sections range from 150 to 250 students and use a commercial textbook and the associated online homework system (Mason et al., 2015) to provide a common resource for students. All participants attended the same lecture section of B1; the instructor was aware of this study and provided researchers with context about the information being taught. This lecture section incorporated regular in-class exercises in which students were asked to engage with material being taught and encouraged to work in groups. Furthermore, students participated in five modeling activities throughout the semester, in which they constructed representations of a system and then were required to predict and explain the biological processes involved. K.P.K. sat in on the lectures for both this course and the chemistry course from which participants were selected. GC1 is listed as a prerequisite or co-requisite for B1. However, less than $25 \%$ of students take B1 and GC1 concurrently.

Study Participants. The call for participants was made in the GC2 course during the last 2 weeks of the Spring 2015 semester, with a small amount of extra credit offered as compensation for participation. The first 14 volunteers who met the qualifications were included in the study. Qualifying participants had taken GC1 in Fall 2014 and both GC2 and B1 in Spring 2015, were in CLUE lecture sections for both GC1 and GC2, and had taken the preselected B1 lecture section. These qualifications were selected because we wanted the students to have shared a recent experience that would allow them to provide informed commentary. The other 385 volunteers were given an alternate activity to complete for extra credit. Of the 14 participants, nine were female and five were male; all were interested in pursuing careers related to biological science or a health profession. Twelve of the students were finishing their first year, and two were finishing their second. Of the 14 students, eight earned a 3.5 or above in all three of the relevant courses. And, on average, they earned a 3.8 GPA in GC1, 3.5 in GC2, and 3.4 in $\mathrm{B} 1 .^{2}$ Students were notified of their rights as research participants and were provided informed consent before participation in the study. Students were given pseudonyms to protect their anonymity.

\section{Interview Protocol}

The first half of the protocol ${ }^{3}$ was inspired by the disciplinary core ideas of the Framework (NRC, 2012). The goal was for students to discuss any connections they felt existed between the courses and what, if any, conflicts they perceived between the material discussed. Because we asked students to discuss an entire year of science course work, the protocol was designed to allow time for reflection and discussion of each course before having students attempt to compare and make connections between the courses. Beginning with general chemistry (GC1/GC2), students were first asked to brainstorm a list of things they had learned and then to describe what the big ideas ${ }^{4}$ or take-home messages were. Notably, while instructors had defined core ideas in both GC1/GC2 and B1, students often came up with their own. After repeating this process for B1, students were prompted to compare their courses and describe how they perceived the concepts to be related.

The second half of the protocol was inspired by the crosscutting concepts of the Framework (NRC, 2012; described during the interviews as "themes that span chemistry and biology"). Students were given the opportunity to generate their own themes before being asked about two in particular-energy and the relationship between structure, properties, and function. For the purposes of this paper, we will refer to the relationship between structure, properties, and function as the SPF relationship. However, it is not meant to imply a single predetermined order, hierarchy, or relationship between these concepts, as those were open to interpretation by the students. Additionally, students could (and did) selectively include the concepts that they felt were relevant within a given context.

At the beginning of the SPF relationship portion of the interviews, students were first asked what each term (i.e., structure, properties, and function) meant to them. They were then asked to describe how they believed the terms were related. Once a shared understanding of a student's interpretation of the SPF relationship was established (including instances in which it varied based on the context), he or she was asked why it would be considered a theme, how it was discussed in each of the courses, and to describe the relative emphasis and importance of the relationship in each course.

\section{Data Collection and Analysis}

The 14 interviews varied in length from 70 to 150 minutes, depending on the amount of information provided by students, who were told that they could terminate the interview at any time. However, all participants had a great deal of information to impart and willingly stayed longer than we had anticipated. Students used a Livescribe pen to create lists of ideas and enhance their descriptions with diagrams and drawings, which allowed audio data to be collected in conjunction with their constructed responses. Additionally, a digital recorder was used as a backup audio source. Data collection and analysis were undertaken from a phenomenographic perspective, as our intention was not to categorize what students do or do not know, but instead to provide a rich description of the various ways that students related their experiences taking introductory chemistry and biology.

${ }^{4}$ Meant to be synonymous with "core ideas" (NRC, 2012), the term "big ideas" was used to align with the language used by instructors during GC1/GC2 and B1.
${ }^{2}$ Distribution of student grades available in Kohn et al., 2018.

${ }^{3}$ The entire interview protocol can be found in the supplemental materials of Kohn et al., 2018. 
The audio data were transcribed verbatim by a professional transcription service and then reviewed and edited for both accuracy and completeness by K.P.K. To gain a holistic understanding of each student interview, the entirety of the transcript was read, and summary notes were taken. However, due to the length and depth of the interviews, all references to the SPF relationship were excerpted for further analysis. While most of the data herein are from the portion of the interviews during which the SPF relationship was the focus, any discussion of the SPF relationship by the student was used to inform our analysis. The SPF relationship excerpts were iteratively open-coded to gain a sense of the breadth of student responses and to identify any emergent areas of discussion. The resulting codes were organized by research question for subsequent analysis. Answering RQ1 was relatively straightforward, as students were directly asked to describe how they think of structure, properties, and function. RQ3 was directly addressed via the following interview prompt: "Can you describe how you see these ideas as being related to each other?" However, students often returned to this idea throughout the interview in response to other prompts. Similarly, students compared their experiences with regard to the presentation of the relationship in their introductory chemistry and biology courses (RQ2) throughout the interviews. For this reason, additional rounds of coding were conducted for each research question, with the specific aim of identifying any variation in opinion or subtleties in students' perceptions. The authors then met to discuss the findings, review contextually situated excerpts, and select representative quotes. Additional quotes can be found in the Supplemental Material. To improve readability, we have removed vocal fillers from the transcript excerpts presented here.

\section{FINDINGS}

The purpose of this study was to explore student conceptions of structure, properties, and function and the relationship between these concepts after having been exposed to structure-property and structure-function relationships in their introductory chemistry and biology courses, respectively. Three closely connected research questions were posited. To understand students' perspectives and the associated context, we wished to explore (RQ1) how students understood the component concepts of structure, properties, and function and (RQ2) how they understood the relationship in each of their courses. RQ1 and RQ2 provided additional insight for our final research question, which asked how students described the relationship between structure, properties, and function (RQ3).
RQ1: How Do Students Coenrolled in Introductory Chemistry and Biology Courses Describe the Meanings of the Terms "Structure," "Properties," and "Function"?

During the interview, the terms "structure," "properties," and "function" were introduced together as being associated with a theme that spans chemistry and biology. In general, students appeared to have little difficulty describing structure and properties, providing examples that ranged from the atomic-molecular to macroscopic scales and across disciplines (Table 4). For function, while some students attempted to provide an example situated in chemistry (e.g., metals being used as wire, compounds acting as medication), most described the concept as more relevant in B1 (Appendix B in the Supplemental Material). As such, most students interpreted structure, properties, and function in ways that were consistent both with each other and with disciplinary expectations.

Structure was generally described based on the underlying components and their arrangement in space. For example, structure was defined broadly as "how something is set-up and what it's made of" (Priyah) and "the arrangement of things in another thing" (Natalie). Students typically mentioned examples that included the word "structure," but these varied by both scale (from the atomic-molecular to the cellular level) and discipline (e.g., Lewis structures vs. the four levels of protein structure). When discussing properties, students tended to provide examples rather than a general definition (Table 4). Those who did define the term stated that properties were "characteristics everything has" (Joseph) or "adjectives to describe the structure" (Lida). Again, the examples that students provided were not confined to a particular scale. Properties that could be used to describe a single molecule, such as electronegativity, acidity, and polarity, were common, but macroscopic properties such as phase (i.e., solid, liquid, or gas), boiling point, and those used for materials (e.g., hardness, malleability) were also mentioned.

It is important to keep in mind that this was the first time students were asked to discuss these terms (i.e., structure, properties, and function) during the interview, and some appeared to still be in the process of deciding what each meant. For example, Aaron (Appendix G in the Supplemental Material) first indicated that the types of bonds present in a structure would determine its properties. However, he quickly changed his mind, describing the presence of ionic or covalent bonds to be properties themselves. Other concepts (e.g., shape, size, and polarity) were referred to as both structure and properties by various students and in some instances by the same student (e.g., Joseph and John in Appendix C in the Supplemental

TABLE 4. Summary of student definitions and examples ${ }^{a}$

Structure $\begin{aligned} & \text { Definitions: what it is made of, how it is set up, the arrangement } \\ & \text { Examples: atomic structure, molecular structure, cellular structure, four levels of protein structure, Lewis structures, shape, size, } \\ & \text { type of bonds, interactions polarity, charge }\end{aligned}$
Definitions: characteristics, adjectives
Examples: shape, size, types of bonds or interactions, polarity, electronegativity, reactivity, boiling point, phase, color, malleability,
hardness
$\begin{aligned} & \text { Definitions: the purpose, the job, the role it plays, what it is supposed to do, what it does, how it works, why something occurs } \\ & \text { Examples } \text { : DNA stores information, mitochondria produce energy, enzymes catalyze reactions, compounds as medication, } \\ & \text { conductive metals used in wiring }\end{aligned}$

attalicized examples were mentioned during discussions of both structure and properties.

${ }^{b}$ More examples of how students attempted to consider function in chemistry can be seen in Appendix B in the Supplemental Material. 
Material). For John, the ambiguity may have been related to how his courses presented these concepts. In B1, he described structure and properties as having been "grouped together," saying, "We never used the word 'properties' but like how we talked about structure ... once you start talking about like if it's polar or nonpolar, I would consider those properties." It may be that students could benefit from an explicit discussion of the difference between structure and properties, and the relationship between them, especially at the molecular level. However, some might argue that these concepts are so closely related that the line can and will occasionally blur and that it is more important that students would be able to describe the causal relationship between these concepts in the context of a particular example.

Of the three component terms, students provided the most varied definitions when describing function (Table 4). Six students described function as the purpose or job of a structure. Additionally, Clarice described function as "what each thing is supposed to be doing." These interpretations appear to imply that the role of a structure within a system is both expected and necessary. Function was also characterized as active, as evidenced by Natalie's description of function as "what something does" and Serina's description of function as "how something is going to work." Examples used by students tended to be biological (e.g., proteins can act as catalysts or receptors, DNA stores information); and when asked about function in chemistry, students appeared to have more difficulty (Appendix B in the Supplemental Material), which is unsurprising, given the disciplinary focus on structure-property relationships.

Of the 14 students interviewed, 11 believed function to be more relevant in B1, suggesting a variety of reasons as to why this was the case (Appendix B in the Supplemental Material). As stated by John, the term "function" was not discussed in GC1/GC2. In comparison, "structure determines function" was one of the core ideas presented in B1. Lida's conception of function made it difficult for her to apply the term in chemistry. She defined function as something's purpose, which she described as more applicable in B1. She noted that, in GC1/GC2, there were not "a lot of chemicals that we're actually using to do something with" and that they did not discuss "how this furthers some sort of organism." In this way, Lida appears to assess a thing's purpose based on personal utility or its relevance to the maintenance and support of life, and her conception of "chemicals" does not satisfy these conditions.

Aaron, Daniel, and Joseph expressed no difficulty applying function to chemistry, although this may have been related to a desire to provide a response, rather than having a meaningful understanding of what function might mean. Indeed, only Daniel was able to apply function in a potentially useful way. Daniel described function in GC1/GC2 as having been discussed with respect to interactions between molecules: "In chemistry we talk about [function] as maybe polar and nonpolar structures, how they interact with other polar and nonpolar structures, stuff like that."

Ruth and Priyah proposed ways in which function could be applied in chemistry from a design perspective, even though the connection was not immediately obvious to them. This is particularly apparent in Ruth's discussion of function in chemistry, "it makes me think of-[pause] not much. Maybe I think of like compounds as drugs, or something like that." It is unclear whether Ruth was referring to the molecular-level mechanism of action or the macroscopic effect (e.g., that an analgesic relieves pain), as she did not describe her example in detail. Priyah was also tentative in her response, as if she were still grappling with the concepts.

Priyah: So for metals conducting electricity... that would be their function and-or would that be property? I feel like these are kind of related-well they're all related but these kind of blur together. But they conduct electricity and that relates back to its structure with the electrons and how they can move freely and-I guess the function would be how you could use the metals [for] wires.

Priyah's difficulty distinguishing between properties and function in chemistry is consistent with the fact that many chemists use the terms interchangeably.

The difficulty students had describing function in the context of chemistry was not unexpected. In chemistry, the disciplinary focus is largely on the relationship between structure and properties and, as such, function was not discussed in GC1/GC2. However, chemistry is inherently a part of both natural and built systems, and in the context of those systems, function is relevant. Ruth and Priyah both made such a connection, specifically focusing on designed system functions. They each proposed a possible function based on their chemistry content knowledge. Lida did not attempt to do so, noting that it had not been a topic of discussion in GC1/GC2. The difficulties that these students had are justifiable, as they were provided little in the way of support in making such connections.

\section{RQ2: How Do Students Coenrolled in Introductory Chem- istry and Biology Compare Their Experiences with Regard to the Presentation of Structure, Properties, and Function (and the Relationship between Them) in These Courses?}

Given the differences in disciplinary focus between chemistry and biology, it is not surprising that students recognized variation between their courses. Students described B1 as having focused on the relationship between structure and function, while GC1/GC2 emphasized structure and properties. The courses were also described as having discussed these concepts differently. The presentation in B1 was seen as being more explicit; students noted that their instructor called out "structure determines function" as a big idea for the course on a regular basis. Generally, students reported that the relationship between structure and properties in the GC1/GC2 courses was less explicit, but the idea was implicit in almost everything the course discussed. Even so, students appeared to be able to make connections between their courses despite these differences.

Presentation of the Structure-Function Relationship in B1. During the interviews, students were asked to describe what they would consider the big ideas for each of their courses. Notably, of the seven big ideas presented by the B1 instructor, only two were mentioned by more than one student-structure determines function (7 of 14) and the chemical and physical basis of life ( 2 of 14). As this portion of the interview preceded any prompting regarding the relationship between structure, 
properties, and function, this would suggest that, of all the big ideas discussed in B1, the relationship between structure and function was by far the one most internalized by students. Additionally, four of the seven students who described "structure determines function" as a big idea in B1, also identified it as a crosscutting concept, or theme that spans chemistry and biology. Consider Natalie, who not only recalled both aforementioned big ideas but indicated that they could be related to one another. She was also able to connect these big ideas to chemistry and physics through the inclusion of properties. While she acknowledged that these big ideas had originally been presented by her B1 instructor, she recognized their value, stating that they allowed her to develop an understanding of why things occurred so that she was not required to rely on memorization.

Natalie: [Our B1 instructor] has a whole list of them [big ideas] ... They make sense. And they make it easier to understand. Personally, I think it's easier to learn if you can understand why things are happening than just to memorize ... if you know kind of the reasons behind it or even just a little bit of the physical or chemical properties that are driving these interactions then you can kind of go back and kind of slowly bring yourself to the same conclusion ... I think that structure and function is kind of a theme that spans both biology and chemistry. The way that something is made up affects the way it interacts with other things and the way it functions and what it's meant to do.

Ultimately, 12 of the 14 students spontaneously mentioned having discussed "structure determines function" in B1 at some point during the interview. Even the two students who did not (Lida and Evelyn) displayed familiarity with the component terms and appeared to recognize that a relationship existed between them. Not only was "structure determines function" referred to as big idea in B1, but students described it as being frequently and explicitly discussed in lecture (Table 5), though that did not always result in a clear understanding of the causal relationship between these concepts (e.g., Clarice and Daniel in Table 5).
Emphasis on Structure-Properties in GC1/GC2. Most students (10 of 14) described GC1/GC2 as having focused on the concepts of structure and properties. As Natalie described it,

Definitely the idea of different properties kind of came more from chemistry. The properties of different molecules or atoms ... And I think that function may be a little bit more we talked about in biology because it's more just applying all of these things that we learned in chemistry about structure and properties.

However, some students continued to include function when talking generally about presentation of the relationship in GC1/ GC2. This may be due to the organization of the interview protocol, which asked students to alternate between discussing GC1/GC2 and B1 individually and comparing them. Additionally, students described it as having been more subtly incorporated into GC1/GC2 than B1 (e.g., Louanne; Tables 4 and 5). Rather than discussing the relationship explicitly, students recognized it as having been incorporated into how the course was organized and the structure of questions on exams and homework assignments (e.g., Lida and Natalie; Table 6). Lida noted that describing the relationship between the terms had felt "natural," based on her experiences in GC1/GC2. Conversely, Evelyn (Table 6) described the connections between structure and properties as having been more explicit in GC1/GC2, saying that, while both courses focused on structure, her chemistry instructor supported her ability to think about the relationship. Whereas she felt that she was expected to make those connections on her own in B1.

Making Connections between the Courses. The differences in how structure, properties, and function were discussed, and even the apparent focus on structure-properties in GC1/GC2 versus structure-function in B1 did not appear to hinder students' abilities to make connections between what they had learned in each course (Appendix D in the Supplemental Material). Lida described the benefit of learning about

\section{TABLE 5. Presentation of the relationship in B1: Structure determines function was discussed frequently and explicitly in B1}

Aaron: [Our B1 instructor] literally brings up the big ideas all the time. Let me write one more. [writes 'structure determines function' at the top of the list] This is [their] biggest idea probably ... [Our B1 instructor] brings this up a lot. Every day [they'll] say that.

Clarice: Oh, [our B1 instructor] goes over this, like, every day. How structure determines function ... Every day. Every day [our instructor] has a slide that's, like, "Structure and function is like a big part of what we're talking about today." But I don't always get what [our instructor], I guess is trying to, portray.

Daniel: [In B1] we talk about the structure of DNA and how that affects its function. [Our instructor] always says that, you know, the structure determines function, structure determines function. And I know in the back of my head that structure does play a role in function, but I'm not entirely sure how, I guess ... [Our instructor] definitely does bring it up a lot, that it is a big idea. But sometimes I'm confused, like we were talking about, let's say, the nucleus, and [our instructor] said, "Oh, structure determines function," but I'm not really sure what that means.

Louanne: I think it's really emphasized in biology, a lot ... I just think that it always goes back to it because no matter what we're doing, you have to relate it back to "why it's doing that?" or "what makes it able to do that?" ... This as a whole we probably talk about a little bit more in biology. It's just more prominent.

Natalie: [The big ideas] are repeated again and again. You need to know them to do well on the tests ... Any time you're not memorizing something [in B1] you're kind of applying that [structure determines function] ... I would say that we've done something that has to do with structure and function, at least every unit. Almost every day in lecture. So, yeah, all the time.

Serina: I know we stressed this a lot in biology, how structure determines the function and we, we, like, revisit that idea every chapter, so that is really important, I would say. 
More implicit presentation in GC1/GC2

Joseph: It was a little more underlying in chemistry. It's there, but [our GC1/GC2 instructor] doesn't say it as much as in biology ... Because in biology, like I said, it's one thing that we're widely tested on, and same in chemistry, even though we may not even realize it. A lot of the questions [our GC1/GC2 instructor will] ask, it will start with draw the Lewis structure, which is definitely important. So it's not something that she says, "Property, structure, and function are important." It's just a given, that you should understand that it's important.

Lida: I feel like that's the way that [chemistry] has kind of just been taught. So when you asked me those three and asked how they correlated, it just seemed natural that that was the answer, because I feel like that's how this course has been set up. Even though I don't think that I've been directly told, like, structure, then properties, then function, it just seems like, "Oh, well, that just makes sense to me."

Louanne: I think in chemistry it's just, like, you know that it's there, but it's just a little bit more subtle ... So I think in chemistry, just, like, maybe I understand without having her say, like, what it is, so maybe that's just, like, what she thinks everyone is able to do at this point. And I don't mind that.

Natalie: [In GC1/GC2] I think that it's kind of something that is almost ingrained into your mind so much that you don't really think about it, but I think that if you didn't and if it wasn't really ingrained into my mind through the course work, then I would need to explicitly think about these things. So I think it's useful in pretty much every different homework assignment ... almost every beSocratic [homework] assignment kind of asks us, "Okay, draw this Lewis structure. Okay, now look at—circle this part. Why does it do this? Or why does this happen?" So I think that while we're being guided to do it all along so that we don't have to do it ourselves, I think it would be very difficult to understand any of the things you learn without being able to relate those three things.

Shelly: I don't think I do it explicitly, but I feel it's definitely the progression of thought. Because you do, you have to think-like when you're given a problem, you have to think, "Well okay, I have to draw this out." And then "Okay, I'm looking at this Lewis structure," and then "Well now I have to determine how this does this." So it's not like-I don't think I think, like, "Okay, structure to, like, properties function," like that's the progression of thought in general, just done in progressive ways of with you doing the material itself.

More explicit presentation in GC1/GC2

Aaron: It's a little bit less explicit in bio, I think, just a tiny bit. Only because, more often than not [our GC1/GC2 instructor] really wants us to look at the properties because that's the easiest way to go about solving any sort of problem ... I think [our GC1/GC2 instructor] comes out and says a lot of the time, "You need to know this in order to get to this next step." In bio, it's more self-reliant ... In [GC1], I've already been going about solving problems like that. That helps me go about solving problems like that in bio. Because I find myself having to do that a lot.

Evelyn: The structure part of it was definitely emphasized in both [courses]. We've looked into structures of many things but, like, talking about how that structure, like, gives it the properties that it has, and then what it does, I'd say was definitely emphasized more in chemistry than it was in biology. In biology, it was kind of like you had to put it together yourself.

aStudents referred to both structure-property and structure-property-function relationships when discussing the presentation in GC1/GC2.

structure and properties in GC1/GC2 as a way to develop an understanding of something's function as opposed to just memorizing it (as she had done in high school). Simon found that he would try to follow a process similar to what he had done in chemistry when thinking about structures and interactions in B1. Furthermore, his knowledge of function from B1 allowed him to think about the "bigger picture" in GC1/GC2. For example, why the ability for water to hydrogen bond might be important to "how water functions in the body."

Simon: [In GC1/GC2] Like when you have water, it's easy for you to say that this water molecule will hydrogen bond with this water molecule and, you know that's the end of it ... thinking about that in terms of biology, I can see why it would do that and I can see how that could be important to how water functions in the body. So it just-I guess it helps me understand the bigger picture of what these things really mean.

Ruth described her understanding of the causal relationship between structure and properties from GC1/GC2 as something that she could apply when "thinking of structure going from properties, and then that really changing the function, in biology." These students recognized the value of the knowledge they had gained in each of their courses and how they could make connections between their courses to better understand chemical and biological systems.

Consideration of Properties in GC1/GC2 and B1. However, some students believed that there were times when it was unnecessary to think about the properties involved (Appendix E in the Supplemental Material). For example, Natalie indicated that the connection between structure and function could be understood without considering the relevant properties. However, this did not appear to diminish her belief that it would be "helpful" to understand the properties involved, with her stating that "you couldn't get really a holistic view of [a structure's] function without knowing its properties."

Clarice and Shelly also noted that information about properties was not always discussed. Shelly indicated that this was dependent on the content or example being discussed (even within a course). With respect to GC1/GC2, she said that "the structure determines what properties it has and then the properties, you can use those to determine what the function would kind of would be." However, she was tentative in her response, appearing to hesitate. When asked why, she replied, "Because I could see structure going to function right away without needing to think about the properties, but I guess it all depends on what you're talking about at the time." She provided an example from B1 regarding the facilitation of protein synthesis by ribosomes (Appendix $\mathrm{E}$ in the Supplemental Material). 
Shelly recalled discussing the structure of ribosomes as having both mRNA and tRNA binding sites and noted the function as: "It allows tRNAs to come in and bind to the codons and it's just the function of it. I don't really know any exact properties of it." The superficial way in which Shelly described her example may indicate that she had memorized this particular example in the context of a structure-function framework. Additionally, if this had been a scaffolded activity (as opposed to an example that just came to mind), she might have been able to discuss how certain properties facilitate or disrupt the mRNA or tRNA binding (e.g., the size and shape of the binding pockets and the strength of the binding interactions) and, therefore, protein synthesis. Questions about what students can do with their knowledge must be left to a future study, given that these interviews were conducted to explore student perceptions as opposed to eliciting evidence for their understanding of the content.

Clarice was more confident about the relationship between properties and function, stating that "one leads to the other and you kind of have the basis of structure to understand, like, where the properties come from and then understand, like, the properties to get where, like, the function comes from." However, when discussing how GC1/GC2 and B1 contributed to her understanding of the relationship, she noted that the properties were sometimes overlooked in B1 (Appendix E in the Supplemental Material). She believed that this was possible because they had built up the relationship from structure to properties in GC1/GC2. While Natalie, Shelly, and Clarice each indicated that properties were not always attended to, it did not appear to change how they perceived the causal relationship between structure, properties, and function (see RQ3).

\section{RQ3: How Do Students Coenrolled in Introductory Chemistry and Biology Courses Describe the Relationship between Structure, Properties, and Function?}

Given that students' introductory chemistry and biology courses each emphasized a different combination (i.e., structure-properties and structure-function, respectively), we wanted to explore how (or even whether) students integrated these perspectives into a single, coherent framework. And so, having discussed what structure, properties, and function meant to them, students were asked to describe how these terms related to one another.

Nine students described a causal relationship in which structure determines properties, which determine function $(\mathrm{S} \rightarrow \mathrm{P}$ $\rightarrow$ F; Appendix F in the Supplemental Material). As Evelyn said, "If something has a specific structure, that gives it specific properties, which then gives it a specific job or function." Ruth was also able to make connections between her understanding of the relationship with regard to chemistry and biology despite a lack of any significant support in making those connections on the part of her instructors, "I think [the courses] worked together because I took what I learned in chemistry from structure determining properties, and was really able to apply that when I was thinking of structure going from properties and then that really changing the function, in biology." In comparison, Natalie described a structure-properties connection as well as a structure-function connection but did not immediately relate properties and function.
Natalie: I'd say structure is the basic thing ... I don't know how I would order properties and function. Because structure definitely determines the function of something but I think it also kind of determines the properties it has. So I don't know if you could really say something's-I mean I guess you could say something's properties determine its function.

Natalie did not have a pre-established framework in which all three terms were related. She was most confident in the connection between structure and function. However, she was not sure how properties should be included. Because Natalie felt that structure could determine properties and that properties could be described as determining function, she settled on the linear progression of $\mathrm{S} \rightarrow \mathrm{P} \rightarrow \mathrm{F}$. It is striking that, even without instructional support, these students were able to recognize how the structure-function relationship from B1 and the structureproperties relationship from GC1/GC2 could be connected.

Notably, Lida and Ruth not only described a causal relationship between structure, properties, and function, but also described their ability to use this relationship as a framework for making predictions. For example, Lida described each component of the SPF relationship as necessary to truly understand the next: "You can't tell the function without the properties. You can't tell the properties without the structure." However, she also noted that one could reason backward through the relationship to begin thinking about how or why a function might occur. Similarly, Ruth indicated that she could think about the SPF relationship differently based on what information was provided to her. This suggests that, given the appropriate scaffolding, students could be encouraged to think of the SPF relationship as more than just a theme that spans the disciplines, but also as a tool for thinking about unfamiliar systems or for considering how changes to a structure may affect its capacity to perform a given function (as Ruth noted in Appendix D in the Supplemental Material).

Alternative Relationships. While there was a great deal of consistency in how many of the students described the causal relationship between structure, properties, and function, some students expressed alternative views. For example, three students (Simon, Joseph, and John) indicated that properties determine structure, which determines function $(\mathrm{P} \rightarrow \mathrm{S} \rightarrow \mathrm{F}$ ). Both Simon and John provided biological examples that crossed multiple levels of structural complexity but did not explicitly acknowledge the presence of the underlying structural elements. For example, Simon described the SPF relationship as follows: "I know that structure determines function and I know that the properties will determine its structure, at least to some degree," going on to explain that three-dimensional protein structure is based on properties of the constituent amino acids such as electronegativity and the ability to form hydrogen bonds (Appendix G in the Supplemental Material). In doing so, Simon described structural aspects of the amino acids themselves (i.e., the types of elements and the ways in which they were bonded) that lead to the properties under consideration. Despite making connections between the underlying structural components, the resulting properties, and higher-level structures ( $\rightarrow P \rightarrow S^{\prime}$ ), he chose to define the relationship as having originated with properties. John provided a similar example (Appendix G in the Supplemental Material). But unlike Simon's, his description of the SPF relationship varied 
throughout the interview. Ultimately, John chose not to put the terms in a specific order, describing the SPF relationship as "structure slash properties to function." While he indicated that this was applicable for both chemistry and biology, in practice, he believed GC1/GC2 was more focused on "structure to properties."

Other students described alternative relationships based on a purposeful choice to combine the component terms or a difficulty in distinguishing between them (Appendix G in the Supplemental Material). Serina had particular difficulty describing a clear relationship between the terms, stating that "the function of something has different properties ... the structure has properties and the structure has a function so, I just, those three words are closely related." Ultimately, she decided that structure and properties determine function, though she appeared to lack confidence (Appendix G in the Supplemental Material). While John described the relationship similarly $(\mathrm{S} / \mathrm{P} \rightarrow \mathrm{F})$, he appears to have done so strategically, to represent different ways that he could apply it.

These various alternative relationships were likely influenced by how structure, properties, and function had been presented in B1 and GC1/GC2 (RQ2) and, in some cases, were foreshadowed when students had difficulty differentiating between the terms (RQ1). For example, Priyah indicated that properties and function "blur" in both GC1/GC2 and B1. John perceived structure and properties as having been "grouped together" in B1, which likely contributed to his choice in identifying the relationship as $\mathrm{S} / \mathrm{P} \rightarrow \mathrm{F}$. Additionally while the implicit nature of the discussion of structure-property relationships in chemistry appears to have been sufficient for many students, this may have contributed to other students' inability to distinguish between the component terms and thus influenced their description of the relationship between them.

Nevertheless, most students were able to describe a causal relationship between structure, properties, and function in a way that appears to align with our disciplinary expectations. However, there are clearly students (like Serina, Priyah, and Aaron) who could benefit from more explicit discussion.

Potential Benefits of the SPF Relationship. One outcome of these interviews was the emergence of connections between structure, properties, and function that had not been explicitly emphasized in either the biology or chemistry courses, and the ways in which this relationship might be used. As noted previously, Ruth and Lida described how they could use the SPF relationship as a framework for making predictions, and Simon described how making connection between his courses allowed him to think about his understanding in GC1/GC2 and B1 from a different perspective. Furthermore, Ruth (Appendix D in the Supplemental Material) noted that having discussed the relationship in both courses had made her more attentive to small changes in structure, as those could ultimately lead to important changes in the properties and function. When asked whether she had used her understanding of the relationship in B1, Ruth described an in-class activity on the potential effect of DNA mutation.

Ruth: We did a modeling exercise where we were talking about a mutation, and how that caused a change in the DNA sequence, and how it eventually changed the amino acid sequence, and how that completely changed the structure of a protein, and how that ruined the function.
Further, Shelly (Table 6) described the relationship as a thought process she used (albeit subconsciously) to work through problems. Similarly, Evelyn described it as a "universal thought process," stating that it "applies to everything, almost everything, at least. Like understanding the basic structure, like that's the foundation of it. And then from there that determines its properties and function. I feel like that works for many things in both courses. It's not just one unit." In fact, Joseph and Aaron (Appendix $\mathrm{H}$ in the Supplemental Material) note that they actively applied the relationship to work through problems. Aaron described this as an iterative process that led to a more refined answer.

Unfortunately, while she was able to talk about the relationship between structure, properties, and function during the interview, Evelyn indicated that she had not recognized the benefit of making such connections in either of her courses. When she was studying for GC1/GC2, she said that everything seemed like a "random idea." Similarly, in biology, she "never really put all of the pieces together." Instead, she would memorize the structure, the properties, and the function individually. "I wouldn't find the common theme that, like, that structure leads to that property to that function. I would just memorize rather than find what connects them all." In both courses, Evelyn appeared to convey that her use of memorization could have been avoided had she recognized the value of understanding the relationship between structure, properties, and function.

\section{DISCUSSION AND IMPLICATIONS}

The concepts of structure, properties, and function are inherently connected and have the potential to facilitate the development of conceptual understanding that spans the science disciplines. However, chemists and biologists emphasize this content in different ways (i.e., focusing on structure-property and structure-function relationships, respectively). Little is known about how students understand these concepts and the relationship between them, both within and across their courses, despite the fact that many students are taking introductory chemistry and biology concurrently. We explored student understanding from three angles: through 1) their interpretation of the conceptsstructure, properties, and function-individually; 2) how they compared the presentation of these concepts in GC1/GC2 and $\mathrm{B} 1$; and 3) the connections students described between these concepts.

\section{Structure, Properties, and Function...}

When considering these concepts individually, students appeared to have little difficulty describing structure or properties in the contexts of both chemistry and biology. However, while able to provide a variety of definitions for function in biology, discussing function as it relates to chemistry was more difficult. Only three students (Joseph, Ruth, and Priyah) were able to consider function productively in the context of chemistry, and even then, two of them expressed uncertainty in doing so. The successes of Priyah and Ruth appear to stem from their consideration of materials designed for a purpose (i.e., conductive wire and pharmaceuticals, respectively). This conception of function is more aligned with an engineering perspective (National Academy of Engineering and National Research Council, 2009; NRC, 2012) and could almost certainly be harnessed by instructors to make 
stronger connections to a variety of STEM fields (e.g., biomechanical engineering or catalysis design in chemistry). It is important to note that, in these examples, the scientist or engineer plays an active role in the design, working toward a functional objective. In natural systems, there is no grand architect (despite the implications of describing function as a structure's purpose; Coleman, 1971; Rosenberg and McShea, 2008). Without explicit discussion of these differences, there is likely to be cross-contamination in how students understand function in various contexts. Furthermore, the regularity with which function was discussed from a biological perspective may have made it difficult for students to interpret function from a design perspective.

As chemistry instructors often teach large numbers of both life sciences and engineering students, it would be beneficial to address these different perspectives on function in chemistry classes. To do so successfully will require instructors to engage in cross-disciplinary discussions so that they are aware of the implications the term "function" carries in various contexts. Further, it is important to find a consensus among the disciplines regarding when and how function is discussed. That is not to say that function should be emphasized in chemistry courses to the detriment of developing a coherent and sophisticated understanding of structure-property relationships, but rather that students may benefit from a foreshadowing of how such an understanding can (and will) be applied in future life sciences or engineering courses and, hopefully, be supported in recognizing this understanding as relevant prior knowledge when the time comes for them to apply it (Ausubel, 1968; Novak, 1998). Ultimately, if we do not at least acknowledge the value of learning about aspects of structure, properties, and function in both contexts, some students may not recognize this to be a relationship that spans all of science. An informative starting point for such cross-disciplinary discussions is the Framework (NRC, 2012), as it describes function, in combination with both structure and properties, as a concept that applies to both natural and built systems.

In general, students' perceptions aligned with their instructors' intentions (as presented in course syllabi; Table 3) regarding the focus of their chemistry and biology courses on structure-property and structure-function relationships, respectively. In general, students described structure-property relationships as having been more subtly incorporated into GC1/GC2 than structure-function had been in B1. And, while properties were included in the syllabus as a part of the "structure determines function" big idea, they were perceived as being explicitly discussed relatively infrequently. This suggests that, across both courses, attention to properties was less explicit than that of structure or function. And while this appears to have been unproblematic for many students, it may have contributed to other students' inability to distinguish between the component terms (Appendix C in the Supplemental Material). Although it may not be vital that students know whether size and shape should be considered aspects of structure or properties, for those students (like Aaron) who do not recognize that these are two distinct but related concepts, constructing an explanation describing how subtly different structures can have very different properties might prove difficult (Cooper et al., 2012b, 2013).

\section{....and the Relationship between Them}

Given that GC1/GC2 emphasized structure-property relationships while B1 focused on structure-function, we were not surprised that students had difficulty describing what function in chemistry means or that properties were not always considered in biology. And yet, even without instructional or curricular supports, these students not only made substantive connections between their course work (Appendix D in the Supplemental Material), but nine students converged on a coherent, causal relationship (i.e., structure determines properties, which determine function; Appendix F in the Supplemental Material). This is particularly notable given the difficulty these same students had describing connections between B1 and GC1/GC2 regarding energy (Kohn et al., 2018).

However, even though most students constructed a reasonable framework, it is important to note that there were those who could have benefited from a more coherent and consistent discussion between the courses (e.g., Serina and Joseph). In fact, Evelyn is an example of a student who could clearly describe a causal relationship between structure, properties, and function during the interview, but had not understood the value of considering that relationship during her courses. Instead, she described how she would memorize the individual components without relating them and, as such, everything seemed like a "random idea." Looking back on her courses, she was able to recognize the potential of working to understand the connection between these concepts.

Other students noted ways they benefited from thinking about the SPF relationship. Shelly, Joseph, and Aaron described it as providing a guiding thought process for working through problems (Appendix $\mathrm{H}$ in the Supplemental Material), while Lida and Ruth indicated that it could be used as a framework for making predictions. Lida and Ruth also described what we might consider "backward causal reasoning" (i.e., reason "diagnostically from effect to cause"; Sloman and Fernbach, 2017, p. 58). They suggested that, when given a function, they could consider the aspects of structure and properties that might lead to such a result. This type of reasoning is considered to be both more difficult and more time-consuming than reasoning from cause to effect and indicates their ability to think about the SPF relationship from a more sophisticated perspective. It would be ideal if all our students could benefit from the SPF relationship in this way. For this reason, we propose that chemistry and biology instructors work together to make stronger connections between their courses using the relationship between structure, properties, and function.

Ausubel's theory of meaningful learning (1968) and Engle's concept of intercontextuality (2006) provide insight regarding how instructors can help students recognize the value of making such connections and promote knowledge transfer between their courses. For meaningful learning to occur (as opposed to rote learning, which depends on memorization), students must "consciously and deliberately choose to relate new knowledge to relevant knowledge the learner already knows in some nontrivial way" (Novak, 1998, p. 23). Logically, this requires that students possess relevant prior knowledge and recognize that such connections are both possible and valuable (Ausubel, 1968; Novak, 1998). This means that chemistry instructors must help students develop a strong understanding of the relationship between structure and properties and that both chemistry and 
biology instructors need to emphasize the value of applying that understanding to consider biological systems and to the concept of function, including through the use of assessments, as students often use these to direct their focus (Snyder, 1970; Crooks, 1988; Entwistle, 1991; Scouller and Prosser, 1994; Scouller, 1998; Momsen et al., 2013).

We propose that the SPF relationship could help students and instructors frame the content in chemistry and biology courses as being linked, with the ability to build on prior knowledge and extend to future learning (Engle, 2006; Engle et al., 2011, 2012). Engle and coworkers (2012) theorize that transfer of knowledge is more likely to occur when there is intercontextuality between the learning and transfer contexts, because students are sent the message that what they are learning will have future relevance and utility. She proposes a number of ways that this can be fostered through an expansive framing of various aspects of the learning environment (e.g., the participants, topics, purposes). By describing the SPF relationship as a common framework that spans chemistry and biology, and by being explicit with students about when and how they can make connections between their courses, instructors can promote intercontextuality. Additionally, the SPF relationship can be presented as a framework for considering unfamiliar phenomena, making predictions, and constructing explanations, as noted by both the Framework (NRC, 2012) and our interview participants. Finally, we believe that understanding the relationship between structure, properties, and function can support deeper understanding of other disciplinary core ideas and crosscutting concepts (e.g., emergence, cause and effect; AAAS, 2011; NRC, 2012; Cooper et al., 2017). By building up student understanding of the SPF relationship in both chemistry and biology and supporting connection-making between the disciplines, we may be able to help students recognize the value of their prior knowledge and encourage its application.

It is important to note that, while we advocate for more explicit discussion of the SPF relationship in both chemistry and biology classrooms, we recognize that not every system discussed will require an in-depth, causal description. For this reason, instructors should think critically about why their students are learning about a particular system, the learning goals they hope to achieve, and how they might adjust activities and assessments to accomplish these goals.

\section{LIMITATIONS}

The perceptions expressed by students in this study regarding the concepts of structure, properties, and function and the relationship between them may not be generalizable to a larger population. These students were enrolled in introductory chemistry and biology courses transformed by instructors who valued structure-property and structure-function relationships, respectively. Furthermore, the students interviewed were largely successful in these courses. Students situated in other, more traditional learning environments or those who were less successful in their science courses may not respond in the same ways. However, the findings presented here suggest an untapped potential for making cross-disciplinary connections between chemistry and biology courses regarding the relationship between structure, properties, and function.

\section{ACKNOWLEDGMENTS}

We thank Cori Fata-Hartley and Tammy Long for very helpful discussions. This work was supported in part by the Association of American Universities (AAU) Undergraduate STEM Education Initiative, funded by the Helmsley Charitable Trust, and by the National Science Foundation under DUE 0816692 (1359818). Any opinions, findings, conclusions, or recommendations expressed here are those of the authors and do not necessarily reflect the views of the National Science Foundation.

\section{REFERENCES}

American Association for the Advancement of Science. (2011). Vision and change in undergraduate biology education: A call to action. Washington, DC

Amundson, R., \& Lauder, G. V. (1994). Function without purpose. Biology and Philosophy, 9(4), 443-469.

Association of American Medical Colleges. (2009). Scientific foundations for future physicians. Washington, DC.

Aussignargues, C., Pandelia, M.-E., Sutter, M., Plegaria, J. S., Zarzycki, J., Turmo, A., ... Gibney, B. R. (2016). Structure and function of a bacterial microcompartment shell protein engineered to bind a [4Fe-4S] cluster. Journal of the American Chemical Society, 138(16), 5262-5270.

Ausubel, D. P. (1968). Educational psychology: A cognitive view. New York: Holt, Rinehart, \& Winston.

Bray Speth, E., Shaw, N., Momsen, J., Reinagel, A., Le, P., Taqieddin, R., \& Long, T. (2014). Introductory biology students' conceptual models and explanations of the origin of variation. CBE-Life Sciences Education, 13(3), 529-539.

Bryfczynski, S. (2012). BeSocratic: An intelligent tutoring system for the recognition, evaluation, and analysis of free-form student input (Doctoral dissertation), Clemson University, Clemson, SC. Retrieved January 3, 2017, from https://tigerprints.clemson.edu/all_dissertations/1053

Bryfczynski, S., Pargas, R. P., Cooper, M. M., \& Klymkowsky, M. W. (2012) BeSocratic: Graphically-assessing student knowledge. Proceedings of the IADIS international conference on mobile learning (pp. 3-10) (Berlin, Germany)

Coleman, W. (1971). Biology in the nineteenth century: Problems of form function and transformation. New York: Cambridge University Press.

College Board. (2009). College board standards for college success: Science. Retrieved August 31, 2017, from https://professionals.collegeboard.com/ profdownload/cbscs-science-standards-2009.pdf

College Board. (2014). AP Chemistry course and exam description (rev. ed.) Retrieved November 18, 2016, from https://apcentral.collegeboard.com

College Board. (2015). AP Biology course and exam description (rev. ed.) Retrieved November 18, 2016, from https://apcentral.collegeboard.com

Collins, A., \& Ferguson, W. (1993). Epistemic forms and epistemic games: Structures and strategies to guide inquiry. Educational Psychologist 28(1), 25-42.

Cooper, M. M., Caballero, M. D., Ebert-May, D., Fata-Hartley, C. L., Jardeleza S. E., Krajcik, J. S., ... Underwood, S. M. (2015). Challenge faculty to transform STEM learning. Science, 350(6258), 281-282. https://doi.org/ 10.1126/science.aab0933

Cooper, M. M., Corley, L. M., \& Underwood, S. M. (2013). An investigation of college chemistry students' understanding of structure-property relationships. Journal of Research in Science Teaching, 50, 699-721. https:// doi.org/10.1002/tea.21093

Cooper, M. M., \& Klymkowsky, M. W. (2013). Chemistry, Life, the Universe and Everything: A new approach to general chemistry, and a model for curriculum reform. Journal of Chemical Education, 90, 1116-1122. https:// doi.org/10.1020/ed300456y

Cooper, M. M., Posey, L. A., \& Underwood, S. M. (2017). Core ideas and topics: Building up or drilling down? Journal of Chemical Education, 94(5), $541-548$.

Cooper, M. M., Underwood, S. M., Bryfczynski, S., \& Klymkowsky, M. W (2014). A short history of the use of technology to model and analyze student data for teaching and research. In Tools of chemistry education research (pp. 219-239). Washington, DC: ACS Publications. 
Cooper, M. M., Underwood, S. M., \& Hilley, C. Z. (2012a). Development and validation of the implicit information from Lewis structures instrument (IILSI): Do students connect structures with properties? Chemistry Education Research and Practice, 13, 195-200. https://doi.org/10.1039/ C2RP00010E

Cooper, M. M., Underwood, S. M., Hilley, C. Z., \& Klymkowsky, M. W. (2012b). Development and assessment of a molecular structure and properties learning progression. Journal of Chemical Education, 89(11), 1351-1357.

Crooks, T. J. (1988). The impact of classroom evaluation practices on students. Review of Educational Research, 58(4), 438-481.

Dauer, J. T., \& Dauer, J. (2016). A framework for understanding the characteristics of complexity in biology. International Journal of STEM Education, 3(1), 13

Dauer, J. T., \& Long, T. M. (2015). Long-term conceptual retrieval by college biology majors following model-based instruction. Journal of Research in Science Teaching, 52(8), 1188-1206.

Dauer, J. T., Momsen, J. L., Bray Speth, E., Makohon-Moore, S. C., \& Long, T. M. (2013). Analyzing change in students' gene-to-evolution models in college-level introductory biology. Journal of Research in Science Teaching, 50(6), 639-659

DeFever, R. S., Bruce, H., \& Bhattacharyya, G. (2015). Mental rolodexing: Senior chemistry majors' understanding of chemical and physical properties. Journal of Chemical Education, 92, 415-426. https://doi.org/ 10.1021/ed500360g

Engle, R. A. (2006). Framing interactions to foster generative learning: A situative explanation of transfer in a community of learners classroom. Journal of the Learning Sciences, 15(4), 451-498.

Engle, R. A., Lam, D. P., Meyer, X. S., \& Nix, S. E. (2012). How does expansive framing promote transfer? Several proposed explanations and a research agenda for investigating them. Educational Psychologist, 47(3), 215-231.

Engle, R. A., Nguyen, P. D., \& Mendelson, A. (2011). The influence of framing on transfer: Initial evidence from a tutoring experiment. Instructional Science, 39(5), 603-628.

Entwistle, N. J. (1991). Approaches to learning and perceptions of the learning environment. Higher Education, 22(3), 201-204.

Ferrari, M., \& Chi, M. T. (1998). The nature of naive explanations of natural selection. International Journal of Science Education, 20(10), 1231 1256.

Function. (n.d.). Merriam Webster. Retrieved December 1, 2017, from www merriam-webster.com/dictionary/function

Goel, A. K., de Silva Garza, A. G., Grué, N., Murdock, J. W., Recker, M. M., ... Govindaraj, T. (1996). Towards design learning environments-l: Exploring how devices work. In International conference on intelligent tutoring systems (pp. 493-501). Montreal, Canada: Springer.

Golick, D., Dauer, J., Lynch, L., \& Ingram, E. (2017). A framework for pollination systems thinking and conservation. Environmental Education Research. https://doi.org/10.1080/13504622.2017.1349878

Hmelo, C. E., Holton, D. L., \& Kolodner, J. L. (2000). Designing to learn about complex systems. Journal of the Learning Sciences, 9(3), 247-298.

Hmelo-Silver, C. E., Jordan, R., Liu, L., Gray, S., Demeter, M., Rugaber, S., \& Goel, A. (2008). Focusing on function: Thinking below the surface of complex natural systems. Science Scope, 31(9), 27-35

Hmelo-Silver, C. E., Marathe, S., \& Liu, L. (2007). Fish swim, rocks sit, and lungs breathe: Expert-novice understanding of complex systems. Journal of the Learning Sciences, 16(3), 307-331.

Hmelo-Silver, C. E., \& Pfeffer, M. G. (2004). Comparing expert and novice understanding of a complex system from the perspective of structures, behaviors, and functions. Cognitive Science, 28(1), 127-138.

Holme, T., \& Murphy, K. (2012). The ACS Exams Institute undergraduate chemistry anchoring concepts content map I: General chemistry. Journal of Chemical Education, 89(6), 721-723.

Huang, X., Patil, A. J., Li, M., \& Mann, S. (2014). Design and construction of higher-order structure and function in proteinosome-based protocells. Journal of the American Chemical Society, 136(25), 9225-9234.

Jordan, R. C., Brooks, W. R., Hmelo-Silver, C., Eberbach, C., \& Sinha, S. (2014) Balancing broad ideas with context: An evaluation of student accuracy in describing ecosystem processes after a system-level intervention. Journal of Biological Education, 48(2), 57-62.
Kohn, K. P., Underwood, S. M., \& Cooper, M. M. (2018). Energy connections and misconnections across chemistry and biology. CBE-Life Sciences Education, 17(1), ar3. https://doi.org/10.1187/cbe.17-08-0169

Mason, K., Johnson, G., Losos, J., \& Singer, S. (2015). Understanding biology, (1st ed.). New York: McGraw-Hill Education

Meijer, M. R., Bulte, A. M., \& Pilot, A. (2013). Macro-micro thinking with struc ture-property relations: Integrating "meso-levels" in secondary education. In Tsaparlis, G. \& Sevian, H. (Eds.), Concepts of matter in science education (pp. 419-436). New York: Springer. Retrieved April 21, 2017, from https://link.springer.com/chapter/10.1007/978-94-007-5914-5_20

Melo, M. N., Arnarez, C., Sikkema, H., Kumar, N., Walko, M., Berendsen, H. J., ... Ingólfsson, H. I. (2017). High-throughput simulations reveal membrane-mediated effects of alcohols on MscL gating. Journal of the American Chemical Society, 139(7), 2664-2671.

Millikan, R. G. (1989). In defense of proper functions. Philosophy of Science, 56(2), 288-302.

Momsen, J., Offerdahl, E., Kryjevskaia, M., Montplaisir, L., Anderson, E., \& Grosz, N. (2013). Using assessments to investigate and compare the nature of learning in undergraduate science courses. CBE-Life Sciences Education, 12(2), 239-249. https://doi.org/10.1187/cbe.12-08-0130

National Academy of Engineering and National Research Council. (2009). Engineering in K-12 Education: Understanding the status and improving the prospects. Washington, DC: National Academies Press.

National Research Council (NRC). (1996). National science education standards. Washington, DC: National Academy Press.

NRC. (2012). A framework for $K-12$ science education: Practices, crosscutting concepts, and core ideas. Washington, DC: National Academies Press.

Neander, K. (1991). Functions as selected effects: The conceptual analyst's defense. Philosophy of Science, 58(2), 168-184.

Novak, J. D. (1998). Learning, creating, and using knowledge: Concept maps as facilitative tools in schools and corporations. Mahwah, NJ: Erlbaum.

Nowinski, A. K., Sun, F., White, A. D., Keefe, A. J., \& Jiang, S. (2012). Sequence, structure, and function of peptide self-assembled monolayers. Journal of the American Chemical Society, 134(13), 6000-6005

Reinagel, A., \& Bray Speth, E. (2016). Beyond the central dogma: Model-based learning of how genes determine phenotypes. CBE-Life Sciences Education, 15(1), ar4.

Rosenberg, A., \& McShea, D. W. (2008). Philosophy of biology: A contemporary introduction. New York: Routledge.

Schwartz, J. J., Mendoza, A. M., Wattanatorn, N., Zhao, Y., Nguyen, V. T., Spokoyny, A. M., ... Weiss, P. S. (2016). Surface dipole control of liquid crystal alignment. Journal of the American Chemical Society, 138(18), 5957-5967.

Scouller, K. (1998). The influence of assessment method on students' learning approaches: Multiple choice question examination versus assignment essay. Higher Education, 35(4), 453-472.

Scouller, K. M., \& Prosser, M. (1994). Students' experiences in studying for multiple choice question examinations. Studies in Higher Education, 19(3), 267-279.

Shane, J. W., \& Bodner, G. M. (2006). General chemistry students' understanding of structure-function relationships. Chemical Educator, 11 $130-137$.

Shirota, Y., \& Kageyama, H. (2007). Charge carrier transporting molecular materials and their applications in devices. Chemical Reviews, 107(4), 953-1010.

Sinha, S., Gray, S., Hmelo-Silver, C. E., Jordan, R., Eberbach, C., Goel, A., \& Rugaber, S. R. (2013). Conceptual representations for transfer: A case study tracing back and looking forward. Frontline Learning Research, 1(1), 3-23.

Sloman, S., \& Fernbach, P. (2017). The knowledge illusion: Why we never think alone. New York: Penguin

Snyder, B. R. (1970). The hidden curriculum. PhilPapers. Cambridge, MA: MIT Press. Retrieved August 9, 2017, from https://philpapers.org/rec/SNYTHC

Talanquer, V. (2017). Progressions in reasoning about structure-property relationships. Chemistry Education Research and Practice. https://doi org/10.1039/C7RP00187H

Tansey, J. T., Baird, T., Cox, M. M., Fox, K. M., Knight, J., Sears, D., \& Bell, E. (2013). Foundational concepts and underlying theories for majors in "biochemistry and molecular biology." Biochemistry and Molecular Biology Education, 41, 289-296. https://doi.org/10.1002/bmb.20727 
Teleology | philosophy. (2016). Encyclopedia Britannica, Retrieved November 14, 2017, from www.britannica.com/topic/teleology

Underwood, S. M., Reyes-Gastelum, D., \& Cooper, M. M. (2015). Answering the questions of whether and when student learning occurs: Using discrete-time survival analysis to investigate how college chemistry students understanding of structure-property relationships evolves. Science Education, 99, 1055-1072. https://doi.org/10.1002/sce.21183

Underwood, S. M., Reyes-Gastelum, D., \& Cooper, M. M. (2016). When do students recognize relationships between molecular structure and properties? A longitudinal comparison of the impact of traditional and transformed curricula. Chemistry Education Research and Practice, 17, 365-380.

Wang, Z., Hsieh, P.-H., Xu, Y., Thieker, D., Chai, E. J. E., Xie, S., ... Liu, J. (2017) Synthesis of 3-O-sulfated oligosaccharides to understand the relationship between structures and functions of heparan sulfate. Journal of the American Chemical Society, 139(14), 5249-5256.

Yen, J., Helms, M., Goel, A., Tovey, C., \& Weissburg, M. (2014). Adaptive evolution of teaching practices in biologically inspired design. In Goel, A. K., McAdams, D. A., \& Stone, R. B. (Eds.), Biologically inspired design (pp. $153-$ 199). London: Springer-Verlag. 